\title{
LEVEL OF EVIDENCE FOR REASONABLE ASSURANCE GUIDES TO PREDICTION
}

Donald G. Schweitzer and Cesar Sastre

April 1987

DONALD G. SCHWEITZER, HEAD

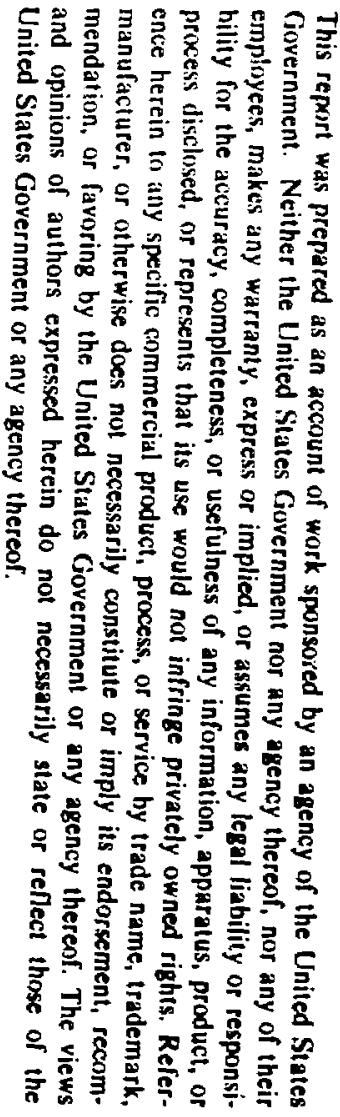

DOE RADIOACTIVE WASTE MANAGEMENT DIVISION

DEPARTMENT OF MUCLEAR ENERGY

BROOKHAVEN MATIONAL LABORATORY

ASSOCIATED UNIVERSITIES, INC.

UPTON, LONG ISLAND, NEW YORK 11973

Prepared for the

OFFICE OF CIVILLAN RADIOACTIVE WASTE MAMAGEMEMT UNDER CONTRACT NO. DE-ACO2-76CHOOO16 WITH THE UNITED STATES DEPARTMENT OF ENERGY 


\section{DISCLAIMER}

This report was prepared as an account of work sponsored by an agency of the Cnited States Government. Neither the United States Government nor any agency thereof, nor any of their employees, nor any of their contractors, subcontractors. or their employees. makes any warranty, express or implied, or assumes any lekal liability or responsibility for the accuracy. completeness, or usefulness of any information. apparatus. product, or process disclosed, or represents that its use would not infringe privately owned rights. Keference herein to any specific commencial product. process. or service by trade name, trademark. manufacturer, or otherwise, does not necessarily constitute or imply its endorsement, recommendation, or favoring by the United States Government or any akency, contractor or subcontractor thereof. The views and opinions of authors expressed herein do not necessarily state or reflect those of the United States Government or any agency, contractor or subcontractor thereof.

Printed in the United States of America

Available frmm

National Technical Information Service

U.S. Department of Commerce

5285 Port Royal Road

Springfield, VA 22161

NTIS price codes:

Printed Copy: A02; Microfiche Copy: A01 
ABSTRACT . . . . . . . . . . . . . . . . . . . . . . . . v v

1. INTRODUCTION ............................ 1

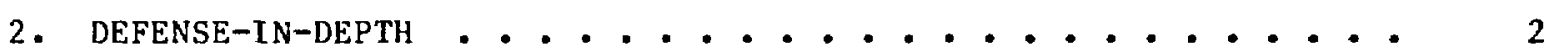

3. Diverse CANdidate MATERIAls . . . . . . . . . . . . . 2

4. TAILORED BACKFILlS . . . . . . . . . . . . . . . . . 2

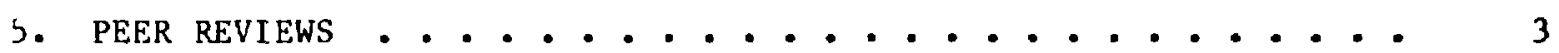

6. BACK-UP POSITION . . . . . . . . . . . . . . . . . 3

7. LEVEL OF EVIDENCE FOR POSITIVE DECISIONS OF REASONABLE ASSURANCE . . . . . . . . . . . . . . . . . 5

7.1 Uncertainty Requirements . . . . . . . . . . . 5

7.2 Uncertainty and Prediction ............... 6

7.3 Accelerated Tests and Predictions............ 7

7.4 Conservative Arguments . . . . . . . . . . . 8

7.5 Potentially Predictable Systens ............ 8

7.6 Potentially Unpredictable Systems ............ 9

7.7 Absence of Adverse Phenomena ............... 11

7.8 Potential for Problem Resolution . . . . . . . . . 12

7.9 Use and Limitations of Peer Review ............ 13

8. CONCLUSTONS . . . . . . . . . . . . . . . . . . . 14 
Over the past years, the DOE Contractors have produced a great deal of work that has been extensively reviewed and criticized by the Nuclear Regulatory Commission (NRC), the Matertals Review Board (MRB) of the DOE, the Advisory Committee on Reactor Safeguards (ACRS), and the technical support group at Brookhaven National Laboratory (BNL). Common aspects of the zeviews and criticisms have provided information on the level of evidence required by the scientific community to defend performance clains. Important indicators of the type of evidence that the NRC will require for favorable decisions of reasonable assurance also can be obtalned from $10 \mathrm{CFR} 60$ and its rationale, from NRC guides and Technical Position papers, from past reviews of the DOE programs by NRC Contractors, and from the use of reasonable assurance by the NRC in its 1984 Waste Confidence Decision.
\end{abstract}

Thi: report describes general concepts related to the acceptability and unacceptability of the level of evidence needed to defend claims with reasonable assurance. The concepts were formulated on the basis of analyses of the NRC position papers, and of common aspects of the reviews and criticisms dealing with compliance demonstration. 
In preparing its licersing strategy, the DOE will be required to make early decisions on what it considers to be acceptable demonstrations of reasonable assurance. There arc likely to be several definitions of reasonable assurance. Each will be dependent on the type of evidence used in the license submittance. The claim that there is reasonable assurance that the corrosion rate of copper at $60^{\circ} \mathrm{C}$ is less than a given value will involve different arguments from those used to defend the claim that there is reasonable assurance that safe disposal of high-level waste is technically feasible.

Important indicators of the type of evidence that the NRC will require for favorable decisions of reasonable assurance can be obtained from 10 CFR 60 and its rationale, from NRC guides and Technical Position papers, from past reviews of the DOE programs, and from the use of reasonable assurance ty the NRC in its 1984 Waste Confidence Decision.

The NRC has already made positive findings of reasonable assurance in dealing with the disposal of high-level waste.

In responding to negative criticisms of the DOE programs, the NRC accepted and deferded the claims made by the DOE in the draft Mission Plan For The Civilian Radioactive Waste Management Program (1984) and in the earlier Statement of Position by the DOE to justify "finding (1)":

"(1) The Commission finds reasonable assurance that safe disposal of high level radioactive waste and spent fuel in a mined geologic repository is technically feasible."

The arguments used by the NRC to defend the finding of reasonable assurance were that the DOE claimed, and the NRC agreed, that proposed DOE programs had the potential to demonstrate safe isolation of high-level waste because they were going to use and evaluate:

(1) A defense-in-depth approach

(2) Diverse candidate materials

(3) A variety of tailored backfills

(4) Peer review of the DOE program

(5) An acceptable back-up position, if needed.

The potential of the proposed DOE program as described prior to 1984, was considered sufficient to justify a favorable finding of reasonabie assurance with the following reservation:

"The Commission's Waste Confidence decision is unavoidably in the nature of a prediction. While the Commission beileves for the reasons set out in the decision that it can with reasonable assurance, reach favorable conclusions of confidence, the Commission recognizes that the possibility of significant uriexpected events remains open. Consequently, the Commission will review its conclusions on waste confidence should significant and pertinent unexpected events occur, or 
at least every 5 years until a repository for high-leve $\overline{1}$

radioactive waste and spent fuel is available."

The spEcific arguments given by the NRC in the Waste Confidence decision were:

2. DEFENSE-IN-DEPTH

"To assure long-term containment, DOE's conceptual design of a waste package is based on a defense-in-depth approach and involves a number of components including spent fuel, stabjlizer (or filler), waste canister, overpack, and an emplacement sleeve. The stabilizer is intended to improve heat transfer from the spent fuel, to provide mechanical resistance to possible canister collapse caused by lithostatic pressure, and to act as a corrosion-resistant barrier between the spent fuel and the canister...... A variety of candidate materials is being considered for these elements. The various waste package components are to be combined in a conservative design that will compensate for the overall technical uncertainties in containment capability."

3. DIVERSE CANDIDATE MATERIALS

"DOE is studying over 28 candidate materials for canisters and overpack. The DOE evaluation program indicates that many of these materials are promising. For example, iron alloys have demonstrated long term durability [DOE], and titanium alloys and nickel alloys show high resistance to corrosion [DOE]. Ceramics are resistant to chemical degradation and have many other desirable properties [DOE].... For more demanding requirements such as brine applications, the alloys of titanium, zirconium or nickel appear to represent alternate choices [DOE]."

\section{TAILORED BACKFILLS}

"In DOE's conceptual design, one engineered barrier consists of backfill materials for filling voids between canister, overpack, sleeve and host rock. The materials are chosen to retard radionuclide migration. The task is to design and test barrier materials which will be effective for very long periods of time. Candidate materials include bentonite, zeolites, iron, calcium or magnesium oxide, tachyhydrite, anhydrite, apatite, peat, gypsum, alumina, carbon, calcium chloride, crushed host rock and others [DOE]." 
"Underlying the pessimism of some participants is apparently a belief that DOE's past record in solving technical problems undermincs the possibility of finding confidence in DOE's ability to solve the waste disposal problems in a timely way.... The qualifications and professional experience of the many scientists and engineers on the overview committees and peer review groups who advise and consult on the DOE program should provide confidence in DOE's efforts [DOE]."

6. BACK-UP POSITION

"The National Research Council after reviewing the Swedish waste disposal work [DOE], concluded that the Swedish waste package could contain the radionuclides in spent fuel rods for hundreds of thousands of years [DOE]."

The NRC and their Contractors have stressed the need for uncertainty analyses and analyses of alternative interpretations. This is likely to be the most important concept in allowing a positive finding of reasonable assurance.

In early definitions and defense of reasonable assurance the Commission in 48 FR 28204 stated (emphasis added):

"In the Commission's view, the 'reasonable assurance' standard neither implies a lack of conservatism nor creates a standard which is impossible to meet. On the contrary, it parallels language which the Commission has applied in other contexts, such as the licensing of nuclear reactors, for many years. See $10 \mathrm{CFR} 50.35(\mathrm{a})$ and $50.40(\mathrm{a})$. The reasonable assurance standard is derived from the finding the Commission is required to make under the Atomic Energy Act that the licensed activity provide 'adequate protection' to the health and safety of the public; the standard has been approved by the Supreme Court, Power Reactor Development Co. v. Electrical Union, 367 U.S. 396, 407 (1961). This standard, in addition to being commonly used and accepted in the Commission's licensing activities, allows the flexibility necessary for the Comission to make judgental distinctions with respect to quantitative data which may have large uncertainties (in the mathematical sense) associated with it."

and in 48 FR 28203:

"As explained in the discussion of Reasonable Assurance, below, uncertainties in the models used in the analysis of repository performance must be considered in the Commission's deliberations on the issuance of a construction authorization or license." 
Further elaboration on the content of reasonable assurance was given in 48 FR 28200 and 28201:

"There are two principal elements that will go into the Commission's application of this 'reasonable assurance' concept. First, the performance assessment which has been performed must indicate that the likelihood of exceeding the EPA standard is low. Second, the Commission must be satisfied that the performance assessment is sufficlently conservative, and its limitations are sufficiently well understood, that the actual performance of the geologic repository will be within predicted limits."

and from 48 FR 28204:

"Even if the calculated probability of meeting the Commission's standards is very high that would not be sufficient for the Commission to have 'reasonable assurance'; the Commission would still have to assess uncertainties associated with the models and data that had been considered. This involves qualitative as well as quantitative assessments. The Commission would not issue a license unless it were to conclude, after such assessments, that there is reasonable assurance that the outcome will in fact conform to the relevant standards and criteria."

"The 1icensing decisions which the Commission will be called upon to make involve additional uncertainties--those pertaining to the correctness of the models being used to describe the physical systems-which are not quantifiable by statistical methods..........this means that modeling uncertainties will be reduced by projecting behavior from well understood but simpler systems which conservatively approximate the systems in question."

In addressing the acceptability of SCPs, the NRC has recently stated:

"Should the range of uncertainties and alternative interpretations and assumptions that can be reasonably supported by the existing data not be considered in the SCP development, the SCP could be deficient in the identification and description of:

(1) The site including the range of uncertainties in known site conditions

(2) The issues and information needed to resclve issues

(3) The issue resolution strategies

(4) The performance allocation (1.e. the definition of performance goals and desired, associated confidence levels for various components of the repository system)

(5) The investigation and study plans (tests and analyses)

(6) The rationales for investigations and studies with consideration to various sources of uncertainty." 


\subsection{Uncertainty Requirements}

The NRC's use of reasonable assurance, and the DOE's strategy planning are intrinsically associated with describing and defending predictions and perfc nance claims.

A severe problem associated with the development of an acceptable strategy occurs when critical predictions and performance claims are stated without bounds and are based on data without addressing the effects of uncertainties in the data.

If, in claiming performance or describing predictions, the reader is provided with assumptions without analyses of the consequences of the assumptions and without analyses of the differences in conclusions that could occur if the assumptions were modified, then evaluations pose major problems. In order to judge the validity of claims and predictions made under these conditions, the reader may be required to be better informed and to do more work than the authors of the claims. The problem has been noted repeatedly, and arguments without uncertainty analyses have been declared as unacceptable in the present regulatory framework.

This leads to an obvious requirement for the justification for a finding of reasonable assurance:

A. If the uncertainties cannot be defined, the clain cannot be defended.

$\star \star \star * \star * * * * *$

Pitting is a poorly understood localized failure mode that is dependent on both macroscopic and microscopic properties of the metal and of the environment. Initiation of pitting can depend upon chemical, mechanical, and thermal inhomogeneities on the surface of the metal. The rate of pitting and the depth to which a pit can progress can be dependent on temperature, temperature gradients, $\mathrm{Eh}, \mathrm{pH}$, ion species, ion concentration, dissolved gases, solute cone zntration gradients, diffusion of reactants and reaction products to and from the surface of the pit, and the direction of gravity. The environmental factors affecting the rate and depth of pit formation are the microscopic values in and near the pit. These values can be significantly different from the average values of the macroscopic environment.

This leads to a rule for uncertainties associated with localized failure and degradation mechanisms:

B. Uncertainties in the nicroscopic environents associated with localized failure echanisms are generally greater than the uncertainties in the macroscopic environments.

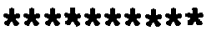




\subsection{Uncertainty and Piediction}

Many strategies for containment by corrosion resistant metals and controlled release by dissolution of the waste forms involve non-equilibrium processes that approach uncertain final states. Although the science of chemical kinetics can be used with severe limitations to predict non-equilibrium changes that tend to approach equilibrium final states, there is no valid method for long-term prediction of non-equlibrium systems evolving towards 111-defined end states.

In the absence of the classic test of substituting equilibrium concentrations to check the validity of an isothermal rate expression at long times, a great deal of highly precise work is necessary to identify and defend an isothermal rate law for a multi-component heterogeneous system. For such systems, the kinetic expression at any given temperature is a composite from many processes only one of which is generally rate determining. In principle, each process has its own temperature dependence, making it unlikely that the same process is rate determining at all temperatures. In practice, the energy barrier that prevents the unstable reactants from instantaneously forming more stable products can be estimated from manipulation of precise isothermal rate expressions over narrow temperature ranges. Since different processes may have similar barriers, justification of the use of these techniques over large temperature ranges, requires that all the factors affecting the isothermal rate at any one temperature also appear in the same mathematical form at every other temperature. Experience has shown that for the corrosion, oxidation, and dissolution phenomena Involved in waste isolation, the uncertainties associated with the data recessary for chemical kinetics and the uncertalnties in the kinetic expressions themselves, will very likely preclude successful justification for kinetic predictions of this type.

The problem is even further complicated by the fact that many of the individual components involved in reactions with other components are subject to slow long-term internal changes affecting their properties and their roles in reacting.

This leads to two observations related to the defense of prediction of property changes through chemical kinetics:

C. Intrinsic uncertainties in data and theory make it unlikely that chenical kinetics can be used for long-tern prediction of property changes in systens evolving towards 111-defined end states.

D. Intrinsic uncertainties in data and theory ake it unlikely that teaperature can be used as an accelerating variable for long-tern prediction of property changes in systens evolving towards ill-defined end states.

$\star * t * k+* * * k *$ 


\subsection{Accelerated Tests and Prediction}

Serious problems can be associated with strategies that depend upon predicting property changes in thermodynamically unstable materials even when the end state may be defined.

Consider the problem associated with predicting radionuclide specific releases from spent fuel over 10,000 years in an environment containing moisture, air and changing temperatures. Over the 10,000-year period the engineered portion of the repository will change from above $200^{\circ} \mathrm{C}$ to below $60^{\circ} \mathrm{C}$. Compliance with the controlled release part of the existing regulation requires that the amount of water leaving the engineered barrier system is known on an annual basis and that the amount of each radionuclide in the water can be acceptably upperbounded on an annual basis for the 10,000 years.

Ignoring spent fuel gap inventories, the bulk of the the radionuclide inventory is initially retained in a thermodynamically unstable matrix. At temperatures of concern, pure $\mathrm{UO}_{2}$ is unstable and should convert to $\mathrm{UO}_{3}$. Irradiated $\mathrm{UO}_{2}$ is more unstable than pure $\mathrm{UO}_{2}$ because of chemical potential increases resulting from the presence of non-equilibrium amounts of fission products. Additional thermodynamic instability arises from the excess lattice energies and crystalline stresses resulting from the quenching of thermal spikes, from the fission products and from the non-stoichlometric amounts of excess oxygen resulting from the fission process. All the above factors depend upon the degree, and to some extent, on the nature of the burn-up. In principle, the matrix should change with time from non-stolchiometric $\mathrm{JO}_{2}$ to a more stable form of $\mathrm{UO}_{3}$. This conversion goes through a number of intermediate uranium oxides which result in large volume changes and in crystalline and internal surface changes redistributing the radionuclides and consuming the excess oxygen from fission. In agreement with theory, small amounts of a hydrated form of $\mathrm{UO}_{3}$ have been determined to form from unirradiated uranium dioxide over a 15-year period in a laboratory experiment at room temperature (Wadsten, T., J. Nuc. Mater. 64, 315, 1977). Nevertheless, it is not possible at present to predict the time dependence of such transformations in spent fuel because of the very large number of ill-defined factors that can affect such changes. For irradiated $\mathrm{UO}_{2}$ containing appreciable but varying amounts of fission products, it is, in fact, not clear what the thermodynamically most stable states are over this temperature range.

Leaching and matrix dissolution depend upon the oxidation state of the matrix, the microscopic crystalline surface areas and surface energies, the distribution of the radionuclides, the possible catalytic or inhibitive effects of impurities and/or excess oxygen, the grain boundary compositions etc. Recognizing that all of these can vary with burn-up and with time, defense of predictability of radionuclide specific release rates on an annual basis for a 10,000-year period in a system of such complexity will require more than conventional extrapolation of high temperature oxidation rates to lower temperatures. Predictions of changes in reaction rates are not equivalent to predictions of the changes in properties associated with the rates. Claims that there may be long periods of time where releases vary from below acceptable values to above acceptable values during the 10,000 years may be impossible to disprove. The existing regulation requires compliance with 
release rates on an annual basis. The use of longer times to allow fluctuations within an acceptable average release has been rejected because it is not possible to defend unequal releases to different generations.

W. Accelerated tests used to predict reaction rates, way not be valid predictors for the property changes associated with these rates.

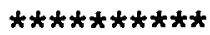

\subsection{Conservative Arguments}

The NRC in Staff Technical Position Papers have warned against the indiscriminate use of temperature as an accelerating variable and indiscriminate use of short-term tests to predict long-term performance. On the other hand, they have also stated (10 CFR 60, 1984 Waste Confidence Decision) that they expect the DOE to use short-term tests as part of the evidence to justify long-term performance if the short-term tests can be shown to be conservative.

F. The acceptability of explicit argunents and evidence defining and defending "bounding" or "conservative" conditions are prerequisites for the acceptability of short-term accelerated experients.

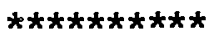

\subsection{Potentially Predictable Systems}

Systems in equilibrium do not change.

This leads to an obvious rule for acceptable long-term prediction:

G. The absence of changes is predictable.

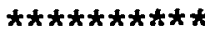

Thermodynamically stable materials are materials that can achieve equilibrium with one or more environments. Thermodynamically unstable materials undergo internal changes and cannot achieve equilibrium with any environment.

Many non-equilibrium systems consisting of thermodynamically stable materials approach equilibrium with monotonically decreasing rates. Isothermal diffusion from a source that is depleted by the diffusion process decreases with time. Fluid flow under pressure through a fixed orifice decreases as the pressure decreases. Isothermal oxidation of graphite in a fixed amount of air decreases as the oxygen or graphite is reacted. The isothermal reaction rate of fixed amounts of hydrogen and oxygen decreases as water is formed. In many examples the mechanisms involved in the reactions are not understood but the end states are defined. For such systems short-term measurements of the time rate of change can be used to upperbound long-term predictions. 


\title{
H. Theoretical argunents can be used to justify conotonically decreasing changes in sone systens evolving towards known final states. In such sjstem short time measurements can be used to conservatively bound long-tere predictions.
}

\author{
$\star \star \star \star \star \star \star \star \star * \star * \star *$
}

\subsection{Potentially Unpredictable Systems}

Models which assume the radionuclide specific release from the engineered system can be bounded by thermodynamic solubility arguments also are subject to great uncertainties. The required data on mutual solubility effects for systems of this complexity do not exist and are difficult to come by. Such models suffer from the implicit assumption that non-equilibrium phenomena such as colloid and particulate transport processes are inoperative or negligible over the required time periods. To date, this assumption has not proven defensible.

Consider a second example such as brittle failure. Brittle failure has been studied extensively since the late 1800 s and is still not understood. The following discussion is taken verbatim from Juvinall, "Stress, Strain, and Strength", McGraw-Hill, Series in Mechanical Engineering, (1967):

"Brittle fracture is the expected mode of failure of materials like cast iron, glass, concrete, and porcelain. On the other hand, most steels, wrought aluminum, magnesium, brass, etc., are expected to show considerable distortion (and to absorb substantial energy) before fracture can occur. That such is not always the case, at least with steel, has caused engineers considerable embarrassment. Consider, for example, the plight of the engineers associated with the design of the ship illustrated in Fig. 5.3, which fractured at the fitting dock...." (the figure shows the "S.S. Schenectady" broken in two at the fitting dock in Portland Oregon, January 16, 1943. "..... This is not an isolated incident; U.S. government reports cited in [Fipper, C.F., 'The Brittle Fracture Story,' Cambridge University Press, New York, 1962] 1ist 233 ship casualties which so weakened the main hull structure that the vessel was lost or was in a dangerous condition. About two-thirds of the ships involved were of welded construction, with most of the balance being partly welded and partly riveted. It is interesting to note that one riveted tanker broke in two twice and was repaired each time. ..." ".... The brittle-fracture problem has been greatly reduced in ships of modern design. The problem is not completely solved yet, however as evidenced by the breaking in two of two large modern tankers. One was the 'African Queen,' a German ship built in 1955. In December, 1958 she ran aground on a soft sand bar at $45^{\circ} \mathrm{F}$ and fractured 30 min later. More recently, the 'World Concord,' a British tanker of around 40,000 tons, fractured in two in the Irish Sea...." "... Brittle fracture of structural steel has by no means been limited to ships. In fact, this problem became evident in various structures during the very early use of structural steel [Shank, M.E., 'A Critical Survey of Brittle Failure in Carbon Plate Steel Structures 
Other Than Ships,' Welding Research Councll of the Engineering FoundatIon Bu11. 17, January 1954]...." ".....Besides ships, brittle fractures have occurred in such steel members as tanks, bridges, pressure vessels, smokestacks, penstocks, power shovels and gas transmission lines. One of the more notable examples occurred in January, 1919, when the 2,300,000-gal Boston molasses tank, then 3 years old, collapsed. Twelve persons and many horses were killed, most by drowning in molasses. Forty more persons were injured, and extensive property damage occurred. After years of litigation which involved the testimony of many leading authorities, the court auditor stated in his summary that he had 'at times felt that the only rock to which he could safely cling was the obvious fact that at least one-half of the scientists must be wrong.".

The first large scale fracture of a steel bridge was that of a vierendeel welded truss bridge over the Albert Canal at Hasselt, Belgium, in March 1943. Shank discusses the brittle faflure of 21 steel bridges, the most recent being that of the then four-year old Duplessis Bridge, in Quebec, Canada in January 1951. Subsequent to Shank's study, The King's Bridge of Melbourne Australia, failed in July, 1962 about 14 months after its completion.

The above examples illustrate:

I. There is no theory for the tiwe evolution of internal property changes in thernodynanically unstable aterials. Any process dependent on these properties is likely to be unpredictable.

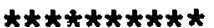

Corrosion of metals and oxidation of porous materials can involve nonmonotonic rate changes. Corrosion is a kinetic, non-equilibrium heterogeneous process. In general, there are more difficulties in predicting rate changes in heterogeneous systems then there are in homogeneous systems. For metals curroding in liquids, the factors that can lead to increases in the corrosion rate with time are:

- increases in surface area

- stress induced fracture of adherent corrosion product films

- precipitation or isothermal annealing in the metal causing increased surface or grain boundary reactivity

- formation and subsequent breakaway of a surface film formed by the corrosion reaction

- depletion of surface components leading to increased surface reactivity

- changes in local pH and chemical composition of the corroding medium due to depletion from reactions with the metal or secondary reactions of the corrosion products

- development of local concentration or aeration cells, etc.

J. A large number of processes can cause non-nonotonic rate changes in metallic corrosion. These processes ay preclude acceptable defense of long-tere prediction of corrosion rates for ulti-conponent ents. 
Equilibrium compounds which form as solid reaction products have unit thermodynamic activity. Variations or uncertainties in the quantities of solid reaction products do not affect the final states or rate of a reaction through chemical theory. Their roles are mechanical, physical, or chemiphysical if they adhere to the solids from which they were formed and develop diffusion barriers for further reaction. Solid reaction products in the form of films can cause non-monotonic reaction rates in isolated systems. Adherent films are known to "breakaway" as they grow and develop stress. Film formation is often associated with changes in the surface composition of the underlying reacting metal. The new surface can react slower or faster than the original surface. Neither theory nor experience provides arguments that can be used to predict long-term changes for rates dependent on film formation.

\section{R. Long-term predictions of rates deternined by filn formation ay not be defensible.}

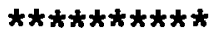

\subsection{Absence of Adverse Phenomena}

For the present DOE design choices, the evidence needed to determine whether it is possible to achieve containment of HLW by a Waste Package and controlled release from an Engineered Barrier System requires state-of-the-art evaluation of the kinetics and thermodynamics of many complex processes. These include corrosion, dissolution and leaching of glass and spent fuel, metastable phase transformations in steels and $\mathrm{UO}_{2}$, heterogeneous radiation reactions, surface sorption and reaction phenomena, and radionuclide movement through diffusion, leaching, and colloidal or particulate transport.

In the existing regulatory framework, the burden of proof is on the applicant for the repositury license. The logic for justifying a performance claim requires the explicit description of the temporal changes in the environment and in the physical and chemical conditions affecting the expected performance. The regulatory agencies evaluating the adequacy of this evidence invoke analyses of the uncertainties in the data and in the models, and require the applicant to provide analyses of the consequences of both favorable and unfavorable predicted performance. Iriplicit in every claim for favorable performance is the assumption that adverse processes do not occur. The present conservative regulatory tenor has imposed a severe burden on the applicant by requiring evidence for the absence of potentially adverse processes and by limiting the use of experiments in which the adverse process was not observed. The absence of potentlally adverse phenomena must be defended by theoretical arguments which are supported by confirmatory null experiments. Because of the inordinately long times over which performance predictions are required, null experiments by themselves bear little weight.

With the important but restrictive exceptions of thermodynamic arguments on perpetual motion, conversion of heat to work, efficiency of Carnot cycles, etc., and obvious violations of phystcal laws, it is in the nature of science to be skeptical about claims of phenomena that will not occur.

This leads to a rule for the elimination of potential faflure mechanisms, degradation mechanisms, or adverse processes: 


\section{The absence of potentially adverse phenomena mut be defended by theoretical arguments supported by conf.1ro;tory null experiments.}

$\star * * * * * * * * *$

\subsection{Potential for Problem Resolution}

Almost no information exists at present which is both necessary and sufficient to quantitatively estimate the likelihood of the occurrence of many potential failure mechanisms in repository environments. Literature dealing with the likelihood of occurrence of potential failure mechanisms generally concludes with recommendations for future studies without discussions of the likelihood that the studies will produce the information needed for problem resolution. Consider the following conclusions obtained from an NRC Contractor study ["Stress-Corrosion Cracking of Low-Strength Carbon Steels in Candidate High-Level Waste Repository Environments," NUREG/CR-3861, BMI-2147, 1987] in which the objective of the study was a literature review to identify potential stress-corrosion cracking agents for low-strength carbon and low-alloy steels in repository environments:

"On the basis of the literature survey, it is recommended that experimental and modeling studies be undertaken to assess the likelihood of stress-corrosion cracking of low-strength carbon steel in waste repository environments. For the identified cracking agents that are present in waste repositories, lower limits in concentration needed to promote cracking must be established. It is important to establish these data under realistic conditions, where synergistic effects of other species in the waste repository are considered..... In addition, physical modeling of potential concentrating mechanisms needs

$:$ to be performed in order to assess more accurately the likelihood that these proposed mechanisms operate and to bound the upper limits of concentration for each mechanism. Identifying and quantifying mechanisms where selective concentration of a single or of a few species occurs is especially important in relating the modeling to the laboratory studies. The models should then be verified through experimentation."

Much of the emphasis on problems associated with the DOE Contractors' waste package programs addresses claims related to containment by metal containers. In BNL reviews we have concluded that claims needed to demonstrate controlled release may be more difficult to defend than those needed for containment. This view is supported by the National Research Council of The National Academy of Sciences. In stressing the advantages of long-term containment vs controlled release in the Swedish Plan for Final Storage of Spent Fuel, the Council claimed:

"The most troubling uncertainties remaining in the KBS proposal relate to the part least likely ever to be relevant to actual repository performance, $1 . e .$, the migration of radionuclides through buffer and bedrock in the improbable event of 
early canister rupture. Uncertainties here are greater simply because of the number of variables that must be considered in any model used to describe the dissolution of radionuclides from fuel rods and their movement through a variety of materials to the point where they may become hazardous to humans. Solubilities, effects of local oxidation due to radiolysis, retardation by sorption of some radionuclides as they migrate through buffer and rock, effect on retardation of the formation of complexes and colloids, dispersion of nuclides into rock along fractures where flow is concentrated-all these must enter into a system of models for radionuclide behavior."

A. Estinates of the likelihood of problen resolution require definitions of both the necessary and the sufficient work needed and evidence that the needed work can be accomplished.

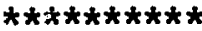

\subsection{Use and Limitations of Peer Review}

Past experience has shown that the the peer review process is resulting in an expanding list of problems requiring resolution. New experts tend to add their special concerns to an already unmanageable list of issues that the Concractors are required to put to rest. Many of these issues have challenged science for decades without significant progress in understanding or identifying the mechanisms involved. Indiscriminate and generic peer review without concomitant procedures for problem resolution is likely to result in continuing negative criticism from the scientific community. Much, if not all of this criticj.sm is accumulating in the public domain. If negative criticism of the DOE programs by members of the scientific community continues to accumulate, and if the existing criticism is not negated through appropriate change, very stringent standards for "Reasonable Assurance" may be predetermined by reviewers and not by the DOE or the NRC. It is unreasonable to expect the NRC to accept and defend DOE claims in license hearings if reputable scientists have already rejected them in prior peer reviews.

Productive use of peer review by the DOE should be focused on specific, high priority issues with explicit methods for problem resolution as prerequisites for conclusion of the review. If the panel of experts used for the review cannot define the necessary and sufficient conditions for problem resolution along with the likelihood of accomplishing resolution to the problem, it should be assumed that the problen is insoluble.

I. Unless the peer review process provides resolutions to the problens being addressed, the number of controversial lssues wil increase and the standards for reasonable assurance wil becone increasingly stringent. If the peer review panel cannot provide means for problea resolution, it should be assuned the problen is insoluble. 


\section{CONCLUSIONS}

A great deal of information exists related to the level of evidence that will be required to demonstrate and defend claims with reasonable assurance. Additional information in the form of reviews by peer groups, by NRC staff and Contractors and by the ACRS can be used to develop guidelines for future programs. In some cases DOE Contractors have taken exception to comments in the reviews. Resolution of the differences is necessary to the development of a successful license application. We believe elaboration and review of the concepts discussed here will be needed by the DOE in developing its license application and in making decisions as to whether or not compliance with existing regulations is technically feasible. 